\title{
A auto-organização da acção táctica: Comentário a Costa, Garganta, Fonseca e Botelho (2002)
}

\author{
Duarte Araújo
}

https://doi.org/10.5628/rpcd.03.03.87

\author{
Faculdade de Motricidade Humana \\ Universidade Técnica de Lisboa, Portugal
}

\section{RESUMO}

Costa, Garganta, Fonseca e Botelho (1) apresentam um estudo sobre inteligência geral e conhecimento específico do jogo de futebol e nível de perícia. Este estudo tem o mérito de estimular o estudo da cognição na acção, bem como de clarificar o papel das horas de prática de futebol no desempenho numa tarefa de inteligência geral. Todavia não respondem às questões fundamentais do seu estudo que são: (i) Qual a relação teórica entre inteligência geral, conhecimento específico do jogo e nível de perícia desportiva? (ii) Será a acção táctica determinada cognitivamente? Estas questões serão discutidas com base no estado actual da investigação internacional. Além disso são apresentadas possibilidades de resposta e de linhas de trabalho assentes na Teoria dos Sistemas Dinâmicos, em que é a partir de uma multiplicidade de factores para além dos cognitivos que emerge o desempenho habilidoso no desporto.

Palavras- chave: inteligência, cognição, decisão, acção, auto-organização, perícia.

\author{
ABSTRACT \\ The self-organization of tactic action: Commentary \\ to Costa, Garganta, Fonseca and Botelho (2002).
}

Costa, Garganta, Fonseca and Botelho (1) studied general intelligence, knowledge specific to the soccer game and skill level. This research has the merit of stimulating the study of cognition in action, and also of clarifying the role of the number of hours of soccer practice in the performance of a general intelligence task. However they don't answer to the fundamental questions of their study: (i) What is the theoretical relationship between general intelligence, specific knowledge of the game and skill level? (ii) Is tactical action cognitively determined? These questions will be discussed based on that paper, and also on international research. Moreover, we will present answer possibilities and research programs based on Dynamical Systems Theory in studying multiple factors beyond cognition where expert performance in sport emerge.

Key Words: Intelligence, cognition, decision-making, action, self-organization, and expertise. 


\section{INTRODUÇÃO}

A fascinante área da tomada de decisão no desporto tem crescido substancialmente nos últimos anos. Um marco importante desta área do conhecimento é o livro de Williams, Davids e Williams (2) que faz uma síntese muito clarificadora do trabalho feito até então na área da percepção visual e da acção no desporto. Todavia, é de notar que há duas abordagens contrastantes nesse livro, uma baseada na psicologia cognitiva tradicional (i.e., no paradigma do processamento de informação) e outra baseada na teoria dos sistemas dinâmicos. De realçar que a perspectiva destes autores é abrangente interligando claramente percepção, cognição e acção.

O recente artigo de Costa, Garganta, Fonseca e Botelho (1) centra-se nesta temática, citando inclusivamente a obra de Williams et al. (2). Uma vez que, tal como afirma António Coutinho, director do Instituto Gulbenkian de Ciência, "a ciência é sobretudo um debate livre de ideias, da positiva complementaridade das diferenças na construção de algo maior", surgiram alguns pontos no referido artigo que apelam a uma profícua discussão. A perspectiva é a de comentar exclusivamente aspectos científicos de modo a enriquecer o trabalho de ambas as partes. Além disso, este comentário esforçou-se arduamente por ser construtivamente crítico, seguindo a premissa de Karl Popper de que uma crítica deve ser dirigida aos pontos fortes de um autor.

Primeiro que tudo é importante referir que Costa et al fazem um interessante levantamento de estudos realizados em Portugal, Brasil e Espanha, na área da cognição no desporto. Este é um primeiro passo para uma sistematização mais alargada do tema, para além da produção anglo-saxónica. Um levantamento inicial como este não só fornece uma referência inicial para os "latinos" interessados no tema, como também estimula a que mais estudos e monografias sejam publicados.

Por outro lado, Costa et al estudam um aspecto premente e actualmente discutido $(3,4,5)$ que é o da qualidade da prática, mais concretamente, estes autores especificam dentro de jogadores com experiência federada semelhante (i.e., os mesmos anos de prática), aqueles que têm diferentes horas semanais de prática. Esta especificação vai ao encontro da teoria da prática deliberada de Ericsson (e.g., 6), que já foi aplicada em desportos colectivos com bola (7), que diz, sumariamente, que a perícia desenvolve-se essencialmente através de um maior número de horas de prática. Portanto um tema actualmente em controvérsia, sobretudo pelo papel secundário que Ericsson atribui à genética.

Há, porém, duas questões que parecem não ser respondidas no artigo de Costa et al. (1), embora sejam aparentemente aquelas que os autores se propõem a responder:

1 - Qual a relação teórica entre inteligência geral (IG), conhecimento específico (CE) do jogo e nível de perícia?

2 - Será a acção táctica determinada cognitivamente?

O termo "aparentemente" surge porque o objectivo do trabalho de Costa et al não foi claramente compreendido por nós. No resumo do estudo ficamos com a ideia que se pretende "comparar a inteligência geral e o conhecimento específico do jogo em jovens praticantes de futebol segundo o nível competitivo" (p.7). Todavia, por exemplo logo na introdução parece que o objectivo não é uma comparação entre níveis competitivos, mas antes, uma relação entre variáveis cognitivas. Esta indefinição tem repercussões no modo como se pode procurar suporte para o objectivo do estudo no resto do artigo. Se o leitor não sabe qual a questão a ser estudada retirará outras ideias da leitura do resto do artigo que não o fundamento e a coerência para a exploração de um dado objectivo.

Contudo, se analisarmos os resultados directamente vemos, pelos dados apresentados, que se pretende comparar jogadores de dois níveis competitivos, quanto à IG e ao CE. Além disso pretende-se correlacionar dentro de cada um destes constructos as variáveis que os compõem, independentemente do grupo a que pertencem os jogadores. Esta clarificação ajuda então a que se perceba que, previamente aos resultados, deverá ser proposta na revisão de literatura introdutória uma resposta para a questão: Qual a relação teórica entre inteligência geral, conhecimento específico do jogo e nível de perícia? Antes de explorarmos de que modo Costa et al respondem a esta questão, é importante destacar que a literatura relativa a esta temática tem levantado a 
necessidade de se clarificar os critérios para distinguir níveis de perícia ${ }^{1}$ (e.g., 8). Costa et al. (1) fazem uma distinção explícita entre os grupos estudados quando, apesar de não revelarem os resultados, afirmam que "as horas de treino semanal constituem a única característica geral em que se verifica a existência de diferenças estatisticamente significativas entre eles" (p.13). Todavia, parece haver outra diferença evidente, pois um grupo compete no campeonato nacional de juniores $\mathrm{B}$ e o outro grupo compete no campeonato distrital da Associação de Futebol do Porto. Ou seja, o pressuposto subjacente a estes dois níveis competitivos é que os jogadores do campeonato nacional têm maior perícia que os do campeonato distrital. Portanto, é nesta procura de explicar os dois níveis de perícia que assenta o estudo, o que é evidenciado na discussão do trabalho.

\section{QUAL A RELAÇÃO TEÓRICA ENTRE INTELIGÊNCIA GERAL, CONHECIMENTO ESPECÍFICO DO JOGO E NÍVEL DE PERÍCIA DESPORTIVA?}

Costa et al. afirmam que o conceito de inteligência é de difícil definição, vago e evasivo. Acrescentam ainda que "reporta-se fundamentalmente a noções e conhecimentos académicos, dado o carácter abstracto de que os estudos habitualmente se revestem" (p.9). Portanto, o conceito de inteligência não parece suficientemente delimitado, sendo um pouco aquilo que se chama a alguém que tem boas classificações escolares, ou que tem classificações elevadas em testes que estão correlacionados com estas classificações (e.g., 9). Além disso o facto de ser abstracto deve-se precisamente a estar distanciado de aspectos comportamentais e de interacção social, sendo portanto mais relevante "identificar os processos que no seu conjunto constituem o comportamento inteligente" $(1$, p.9). Naturalmente que o comportamento surge sempre num contexto, portanto a noção de "inteligência específica para determinado domínio" (p.9), por oposição a inteligência geral e abstracta, parece serenar a controvérsia em torno do conceito. Após esta clarificação, quando já se poderia supor que então há que falar de como se podem avaliar os comportamentos inteligentes em contextos específicos, os autores voltam a reforçar a ideia que a inteligência geral não descrimina os níveis de perícia desportiva. E pelo contrário, um processo cognitivo mais definido, como a orientação espacial geral, já apresenta uma tendência para descriminar níveis de perícia. Costa et al., fazem mesmo uma revisão de estudos, onde mais uma vez não é a inteligência geral, mas antes processos cognitivos como a atenção que estão relacionados com a habilidade desportiva. Portanto concluímos que processos cognitivos gerais (i.e., que não são específicos de um dado contexto), mas mais definidos, como a orientação espacial e a atenção, podem distinguir níveis de perícia desportiva.

Todavia, fica por esclarecer se os comportamentos inteligentes específicos são ou não os mais esclarecedores, tal como antes fora afirmado. Ou se há alguma relação entre comportamento inteligente específico e processos cognitivos gerais, mas definidos, como a atenção. Mas esta dúvida persiste sem que a ligação entre estes conceitos seja feita. Parece então que o único consenso é o de a inteligência geral ser um conceito com muitos pontos fracos.

No ponto intitulado "inteligência $v s$ conhecimento" (p.12) parece que finalmente este aspecto pendente sobre inteligência geral será resolvido. Os autores afirmam "tentar esclarecer, a partir da sua especificidade relativa, que lugar poderá ocupar cada uma destas dimensões num campo único como o desporto" (p.12). Mas, infelizmente, presenciamos apenas uma repetição de frases em espanhol que eventualmente terão escapado aos autores e aos editores da revista. Sendo apenas afirmado que "estudos recentes têm incidido nas interacções entre inteligência e conhecimento" (p.13). Fica também por resolver se os comportamentos inteligentes específicos são aquilo que os autores depois designam como conhecimento específico.

Há um aspecto interessante a referir. Os próprios autores, já na parte da discussão dos resultados, transmitem-nos um pouco mais da sua ideia de inteligência geral que, supostamente, serviria de base a todas as outras inteligências específicas: o mítico factor g que Spearman (10) tanto procurou tendo sempre encontrado múltiplos factores. Costa et al. (1) afirmam que "Quanto a saber se os jogadores mais inteligentes noutras áreas do conhecimento também o são no desporto, a resposta encontrada aponta para que tal não se verifique, até porque as correlações encontradas indicam em sentido contrário e quando positivas atingem valores muito bai- 
xos" (p.14). Apesar destas correlações com determinados valores não se encontrarem no artigo, supõem-se que os autores correlacionaram as variáveis que classificaram ser de inteligência geral com as variáveis classificadas como conhecimento específico. Todavia, os autores parecem não estar convictos deste conceito de inteligência geral, presente em todo o artigo, ao afirmarem que relacionaram a inteligência existente noutras áreas do conhecimento, e não uma inteligência geral subjacente ao conhecimento em qualquer área.

Portanto, em nenhum momento fica claro quais as relações teóricas existentes entre inteligência geral, conhecimento específico e perícia desportiva. Deste modo não se procura com a investigação um resultado que possa ser explicado por nenhuma posição teórica, mas antes explicações a posteriori para os resultados estatísticos encontrados.

Esta procura de uma relação entre o desempenho em tarefas específicas de um desporto, o desempenho em tarefas que medem supostamente componentes gerais a qualquer desempenho e a perícia desportiva, já tem sido perseguida por Starkes desde os anos oitenta $(11,12,13,14)$. A conclusão mais sonante e generalizada é a de que apenas o desempenho em tarefas específicas a um desporto pode predizer uma parte da perícia desportiva (e.g., 8). Mais do que isso, o treino de componentes genéricos ou comuns a qualquer desempenho, como o treino da atenção ou percepção visual genéricas, não revela quaisquer melhorias no desempenho dos atletas (e.g., 15, 16). Contrariando um pouco o modo como as conclusões de Costa et al. (1) são apresentadas (p.17), o único resultado robusto é o de que o indicador psicológico relativo ao desempenho no teste de Raven (17) constitui um bom indicador da perícia desportiva. Ou seja, os jogadores com mais horas semanais de treino são os que têm piores resultados no teste de inteligência geral de Raven, de modo estatisticamente significativo. Supostamente os jogadores menos habilidosos seriam os mais "inteligentes".

Dificilmente a literatura revista pode explicar, à partida, este resultado. As explicações dos autores contornam este assunto. Todas as outras conclusões não foram estatisticamente suportadas pelos resultados. Isto não quer dizer que não haja resultados suportados na literatura. Por exemplo, a correlação positiva entre respostas correctas e tempo de decisão nos jogadores de maior habilidade está amplamente demonstrada na literatura (e.g., 18, 19, 20). Portanto, a assunção fundamental do estudo de Costa et al. (1), de que há uma relação entre IG com CE e com a perícia desportiva, parece não ter fundamento na literatura científica. Talvez a causa desta conclusão surja quando se tenta responder a outra mais fundamental: Será a acção táctica determinada cognitivamente?

\section{SERÁ A ACÇÃO TÁCTICA DETERMINADA COGNITIVAMENTE?}

Conforme defendem Costa et al. o jogo tem natureza contextual, portanto influenciado pelo envolvimento. Estes autores defendem igualmente haver, além dos aspectos contextuais, diversos aspectos morfológicos, funcionais e psicológicos que "caracterizam" (p.8) os desportos colectivos com bola. A influência contextual e de múltiplos factores no desempenho têm tal importância que "os problemas surgidos no jogo obrigam o jogador a decidir e seleccionar qual a solução mais consentânea com a situação" (p.8, nossa ênfase) e também que "o jogo de Futebol reclama dos praticantes uma elevada capacidade perceptiva" (p.8, nossa ênfase), falando-se inclusivamente de imprevisibilidade e aleatoriedade, em concordância com Garganta e Cunha e Silva (21). Estes autores, nessa interessante reflexão de 2000 , apresentam o jogo de futebol como um sistema dinâmico que tende para uma descrição caótica. Ou seja, é um sistema determinístico apesar de ter variabilidade, onde existem regularidades devido aos constrangimentos que o caracterizam (p. ex., a regra), mas cuja sensibilidade às condições iniciais faz com que dentro de um padrão identificável (que é o jogo e as respectivas jogadas) não haja repetitibilidade. Portanto, apresentam o jogo de futebol como um sistema dinâmico aberto, longe do equilíbrio. Dito de outro modo, é um sistema constituído pelos aspectos ambientais, constituído também pela tarefa a desempenhar com as suas estratégias e com as suas regras e constituído pelos jogadores que funcionam autonomamente (com a sua morfologia, fisiologia, cognição, emoção, etc.), apesar de coordenados entre si. Sendo assim, Garganta e Cunha e Silva apresentam o jogo e o comportamento daí resultante como um 
fenómeno emergente, portanto resultante da interacção de vários componentes que "obrigam" e "reclamam" do jogador determinadas acções. Dito de outro modo, o comportamento não é determinado à partida por nenhum destes aspectos em particular, mas antes auto-organiza-se perante a interacção de todos estes constrangimentos.

Costa et al. (1) clarificam ainda mais este ponto afirmando que "o sucesso nos jogos tácticos depende largamente do nível de desenvolvimento das faculdades perceptivas e intelectuais dos atletas, especialmente associadas com outros factores que determinam a performance" (p.8), portanto vincando que o comportamento emerge da interacção de múltiplos constrangimentos.

Todavia, esta base teórica fundamentada na Teoria dos Sistemas Dinâmicos (e.g., 2, 22, 23, 24), para o jogo de futebol é frequentemente contradita por afirmações intercaladas como "a tomada de decisão precede a acção", "os jogadores têm de saber o que fazer, para depois seleccionar como o fazer", "sem se conhecer a essência do jogo e dos seus princípios tácticos, não se pode aproveitar na plenitude os recursos técnicos" (1, p.8). Estas frases claramente indicam que o jogador actua do modo que actua, devido apenas a constrangimentos cognitivos, isto é, o jogador faz o que faz porque decidiu fazer assim. É transmitida a noção de que estes constrangimentos cognitivos são o factor que determina o comportamento, e não a interacção de múltiplos factores, tal como vimos anteriormente. A assunção dos autores nestas frases é a de que a tomada de decisão baseiase em "conhecimento táctico altamente especializado e armazenado na memória de longo prazo" (p.10). Portanto activa-se este conhecimento da memória a longo prazo, supostamente para a memória de trabalho, selecciona-se uma resposta dentro daquelas activadas na memória e envia-se a ordem para que seja executada. A acção resulta de uma solução previamente armazenada na memória (e.g., 25).

Todavia, Costa et al afirmam que "nos JDC, acção é sinónimo de tomada de decisão, porque cada situação requer uma nova solução" (p.12). Mais uma vez é de um conjunto de constrangimentos não só internos, mas também externos, que a acção se torna possível, que se permite que através da acção se resolvam problemas, que agir seja decidir. A explica- ção para este aspecto não pode apenas centrar-se em estruturas de conhecimento na memória, mas antes em processos de emergência e de auto-organização. O jogador não sabe o que o espera "em meio instável e inconstante [onde] o praticante esforça-se em extrair as constâncias e regularidades no conjunto das informações disponíveis" (p.12), que estão naturalmente no contexto.

A perspectiva de que a acção resulta de soluções anteriormente registadas na memória parece contradizer a designação "acção táctica". Este tipo de acção é tido como integrante do processo comportamental de resolução de problemas num contexto de jogo, onde o "movimento desportivo pressupõe uma actividade cognitiva" (p.9). Se o movimento pressupõe uma actividade cognitiva, esta está embutida nesse movimento, em vez de o preceder. Não queremos com isso dizer que não existe actividade cognitiva prévia ao movimento que o possa influenciar. Naturalmente existe, tal como existe movimento prévio que influencia o movimento subsequente, portanto existem vários factores a possibilitar e a influenciar a acção do jogador.

Se a acção táctica é uma "aplicação" (p.9), então não pode existir no vácuo. Pelo contrário, existe claramente manifestada no contexto. Portanto, concordamos com os autores quando dizem "ao jogador é exigido que decida e exteriorize o seu raciocínio ou decisão" (p.8, retiramos os adjectivos "mental" e "cognitiva" que qualificavam respectivamente "raciocínio" e "decisão"). Portanto, é na sua acção que o jogador decide; decide actuando em função daquilo que o contexto lhe reclama, a sua trajectória é o seu raciocínio. Talvez desta perspectiva seja possível compreender que os jogadores peritos tenham "maior consistência e adaptabilidade nos padrões de movimento" (p.9). Se o comportamento fosse determinado previamente a nível cognitivo, a adaptabilidade ao contexto seria impossível, uma vez que o contexto está em constante mudança. No entanto, apesar de toda esta variabilidade contextual e motora, os peritos mantém constantes as suas relações funcionais com o meio. Dito de outro modo, a sua afinação (i.e., focalização) aos objectivos relevantes do jogo mantém-se constante, apesar dos processos que lhe estão subjacentes serem altamente adaptáveis àquilo que o contexto proporciona. Esta adapta- 
bilidade ao contexto não seria possível se as acções fossem determinadas previamente pelos registos em memória (não seria adaptação, mas antes réplica de movimentos anteriores).

Ao pretender explicar as diferenças de perícia dos dois grupos de jogadores, a investigação de Costa et al, ao cingir-se à análise dos constrangimentos cognitivos, descura a noção "emergente" do desempenho. Para se captar a perícia do jogador é fundamental considerar-se a multiplicidade de factores que constrange e faz emergir o desempenho, pois "os jogadores devem ter condições para inventar novos jogos no decorrer do próprio jogo" (p.17).

\section{CONCLUSÃO}

Aparentemente pode parecer difícil levar uma ideia destas a bom porto. Como analisar a totalidade de variáveis que actuam simultaneamente no jogador quando este decide actuando? Parece bem mais plausível a simplificação desta complexidade, estudandose um aspecto de cada vez e perante contextos que não mudam com a acção do jogador, onde o estudo dos aspectos cognitivos estaria a cumprir este princípio. Porém esta simplificação tem as dificuldades anteriormente levantadas. Mas talvez mais importante, o mundo do desporto que já recorre a muitos dos conhecimentos das ciências do desporto, ainda não solicita os conhecimentos obtidos pela psicologia cognitiva do desporto. É de realçar que apesar dos resultados obtidos por essa via já se acumularem há mais de 30 anos, ainda é comum constatar-se a afirmação que processos como a tomada de decisão não são treináveis. Ou ainda mais fatalista, que o talento não é treinável. Contudo, não é fácil para os cientistas do desporto demonstrar que quem tem os seus conhecimentos, consegue desenvolver melhor a habilidade dos jogadores, que aqueles que os não têm. Realçamos que não há dúvida alguma que a psicologia cognitiva do desporto trouxe contribuições fundamentais ao desporto. Mas trouxe também a possibilidade de se explorar outras vias para se obter respostas que esta via não consegue obter. Nesta linha de estudo, tendo por base a Teoria dos Sistema Dinâmicos, existem já diversos trabalhos $(22,23,26,27)$ que apontam nesta direcção. Especificamente, o tema da tomada de decisão tem sido alvo de uma linha de investigação $(28,29)$, que partindo das situações mais simples que podem acontecer em jogo (e.g., 1x1), com todos os múltiplos factores que influenciam o comportamento, analisa como emerge a decisão na acção real. Através da análise cinemática de trajectórias, a tomada de decisão é descrita como um fenómeno de transição de fase, especificada numa quebra de simetria do sistema atacante-defesa-alvo (cesto, baliza, etc.) (cf. 30 ), onde se transita de um estado de equilíbrio (defesa contrabalança acções do atacante), para um estado de desequilíbrio (atacante passa o defesa). Por outras palavras, o sistema descrito evolui até um certo momento, a partir do qual há uma ruptura (quebra de simetria) do estado do sistema, transitando para um novo estado, que corresponde ao momento em que o atacante tem vantagem.

Portanto, há a percorrer um longo caminho onde os esforços dos cientistas do desporto devem convergir para a clarificação de fenómenos complexos como a "acção táctica", que Mahlo (31) pioneira e audaciosamente despoletou. Este esforço passa pela clarificação do que é a acção do jogador, a qual é contextualizada, bem como pelo modo como se teorizam as explicações para este fascinante fenómeno. É este contributo que o presente comentário pretende juntar ao de Costa et al. (1).

Em inglês designada expertise. Como tradução do termo inglês expert, utilizamos o termo "perito", em vez de "experto".

\section{CORRESPONDÊNCIA}

Duarte Araújo

Laboratório de Psicologia do Desporto

Faculdade de Motricidade Humana

Estrada da Costa

1495-688 Cruz Quebrada

Portugal

Daraujo@fmh.utl.pt 


\section{REFERÊNCIAS}

1 Costa, J.; Garganta, J.; Fonseca, A.; Botelho, M. (2002). Inteligência e conhecimento específico em jovens futebolistas de diferentes níveis competitivos. Revista Portuguesa de Ciências do Desporto, 2(4), 7-20.

2 Williams, A. M.; Davids, K.; Williams, J.G. (1999). Visual perception and action in sport. London: E \& FN Spon.

3 Davids, K. (2000). Skill acquisition and the theory of deliberate practice: It ain't what you do it's the way that you do it! International Journal of Sport Psychology, 31, 461-466.

4 Starkes, J. L. (2000). The road to expertise: is practice the only determinant? International Journal of Sport Psychology, 31, 431-451

5 Starkes, J.; Ericsson, K. A. (Ed.). (2003). Expert performance in sport: Recent advances in research on sport expertise. Champaign, IL: Human Kinetics.

6 Ericsson, K.; Krampe, R.; Tesch-Romer, C. (1993). The role of deliberate practice in the acquisition of expert performce. Psychological Review, 100, 363-406.

7 Helsen, W.; Starkes, J. L.; Hodges, N. (1998). Team sports and the theory of deliberate practice. Journal of Sport $\mathcal{E}$ Exercise Psychology, 20, 12-14.

8 Starkes, J.; Helsen, W.; Jack, R. (2001). Expert Performance in Sport and Dance. In R. Singer, H. Hausenblas, C. Janelle (Ed.), Handbook of Sport Psychology (2nd ed.). Chichester: John Wiley, 174-201.

9 Wigdor, A. K.; Garner, W.R. (Ed.) (1982). Ability tests: Uses, consequences, and controversies. Washington, DC: Nat. Acad. Press.

10 Spearman, C. (1904). "General intelligence" objectively determined and measured. American Journal of Psychology, 15, 201-293.

11 Allard, F.; Starkes, J. (1991). Motor skill experts in sports, dance and other domains. In K. A. Ericsson, J. Smith (Ed.), The study of expertise: prospects and limits. Cambridge: England: Cambridge University Press, 126-153.

12 Helsen, W.; Starkes, J. (1999). A multidimensional approach to skilled perception and performance in sport. Applied Cognitive Psychology, 13, 1-27.

13 Starkes, J.; Allard, F. (Ed.) (1993). Cognitive issues in motor expertise. Amsterdam: Elsevier Science Pub. - North Holland.

14 Starkes, J. L.; Deakins, J. (1984). Perception in sport: a cognitive approach to skilled performance. In W. F. Straub \& J. M. Williams (Ed.), Cognitive sport psychology. Lansing, New York: SportScience Associates, 115-127.

15 Abernethy, B.; Wood, J. (2001). Do generalized visual programmes for sport really work? An experimental investigation. Journal of Sports Sciences, 19, 203-222.

16 Williams, A. M.; Grant, A. (1999). Training perceptual skill in sport. International Journal of Sport Psychology, 30, 194-220.

17 Raven, J. (1958). Advanced Progressive Matrices. London: Lewis.

18 Helsen, W.; Pauwels, J. (1988). The use of a simulator in evaluation and training of tactical skills in football. In T. Reilly, A. Lees, K. Davids, \& W. Murphy (Ed.), Science and football. London: Spon, 493-497.

19 Helsen, W.; Pauwels, J. M. (1993). The relationship between expertise and visual information processing in sport. In J. L. Starkes, \& F. Allard (Ed.), Cognitive issues in motor expertise. Amsterdam: Elsevier Science, 109-134.
20 Thiffault, C. (1980). Construction et validation d'une mesure de la rapidité de la pensée tactique des joueurs de hockey sur glace. In C. H. Nadeau, W. R. Haliwell, K. M. Newell, \& G. C. Roberts (Ed.), Psychology of motor behaviour and sport. Champaign, IL: Human Kinetics, 643-649.

21 Garganta, J.; Silva, P. C. (2000). O jogo de futebol: entre o caos e a regra. Horizonte, 91, 5-8.

22 Davids, K.; Handford, C.; Williams, M. (1994). The natura physical alternative to cognitive theories of motor behavior: an invitation for interdisciplinary research in sports science? Journal of Sports Sciences, 12, 495-528.

23 Davids, K.; Williams, M.; Button, C.; Court, M. (2001). An integrative modeling approach to the study of intentional movement behaviour. In R. Singer, H. Housenblas, \& C Janelle (Ed.), Handbook of Sport Psychology (2nd ed.). New York: John Wiley, 144-173.

24 Handford, C.; Davids, K.; Bennett, S.; Button, C. (1997). Skill acquisition in sport: Some applications of an evolving practice ecology. Journal of Sports Sciences, 15, 621-640.

25 McPherson, S. L.; Thomas, J.R. (1989). The relation of knowledge and performance in boy's tennis: Age and expertise. Journal of Experimental Child Psychology, 48, 190-211.

26 McGarry, T; Anderson, D.; Wallace, S.; Hughes, M.; Franks I. (2002). Sport competition as a dynamical self-organizing system. Journal of Sports Sciences, 20, 771-181.

27 Schmidt, R. C.; O’Brien, B.; Sysko, R. (1999). Self-organization of between-persons cooperative tasks and possible applications to sport. International Journal of Sport Psychology, 30, 558-579.

28 Araújo, D.; Davids, K.; Bennett, S.; Button, C.; Chapman, G. (2003) Emergence of Sport Skills under Constraints. In A.M. Williams, N.J. Hodges (Eds.) Skill Acquisition in Sport: Research, Theory and Practice. London: Routledge, Taylor \& Francis. In Press.

29 Araújo, D.; Davids, K.; Sainhas, J.; Fernandes, O. (2002). Emergent decision-making in sport: a constraints-led approach. Communication to the International Congress on Movement, Attention and Perception, Poitiers, France.

30 Kugler, P.; Turvey, M. (1987). Information, Natural Law, and the Self-assembly of Rhythmic Movement. NJ: LEA

31 Mahlo, F. (1969). L'acte tactique en jeu. Paris, France: Ed. Vigot. 